\title{
Knowledge and attitude of pregnant women towards preeclampsia and its associated factors in South Gondar Zone, Northwest Ethiopia: a multi-center facility- based cross-sectional study
}

Maru Mekie ${ }^{1 *}$, Dagne Addisu', Minale Bezie', Abenezer Melkie', Dejen Getaneh², Wubet Alebachew Bayih² and Wubet Taklual ${ }^{3}$

\begin{abstract}
Background: Preeclampsia has the greatest impact on maternal mortality which complicates nearly a tenth of pregnancies worldwide. It is one of the top five maternal mortality causes and responsible for $16 \%$ of direct maternal death in Ethiopia. Little is known about the level of knowledge and attitude towards preeclampsia in Ethiopia. This study was designed to assess the knowledge and attitude towards preeclampsia and its associated factors in South Gondar, Northwest Ethiopia.

Methods: A multicenter facility-based cross-sectional study was implemented in four selected hospitals of South Gondar Zone among 423 pregnant women. Multistage random sampling and systematic random sampling techniques were used to select the study sites and the study participants respectively. Data were entered in EpiData version 3.1 while cleaned and analyzed by Statistical Package for Social Sciences (SPSS) version 23. Descriptive and inferential statistics were performed. Adjusted odds ratio with $95 \%$ confidence interval were used to identify the significance of the association between the level of knowledge on preeclampsia and its predictors.

Results: In this study, 118 (28.8\%), 120 (29.3\%) of the study participants had good knowledge and a positive attitude towards preeclampsia respectively. The likelihood of having good knowledge on preeclampsia was found to be low among women with no education $(\mathrm{AOR}=0.22,95 \% \mathrm{Cl}(0.06,0.85))$, one antenatal care visit (ANC) $(A O R=0.13,95 \% \mathrm{Cl}(0.03,0.59))$. Whereas, those who booked for ANC in the first trimester (AOR $=6.59,95 \% \mathrm{Cl}$ $(1.43,30.33))$, gave the last birth at a health facility $(A O R=2.61,955 \mathrm{Cl}(1.03,6.61))$, and experienced a complication during previous births $(\mathrm{AOR}=3.67,95 \% \mathrm{Cl}(1.78,7.57)$ ) were more likely to be knowledgeable on preeclampsia.

* Correspondence: maru.mekie1@gmail.com

'Department of Midwifery, College of Health Sciences, Debre Tabor University, Debre Tabor, Ethiopia

Full list of author information is available at the end of the article

(c) The Author(s). 2021 Open Access This article is licensed under a Creative Commons Attribution 4.0 International License, which permits use, sharing, adaptation, distribution and reproduction in any medium or format, as long as you give appropriate credit to the original author(s) and the source, provide a link to the Creative Commons licence, and indicate if changes were made. The images or other third party material in this article are included in the article's Creative Commons licence, unless indicated otherwise in a credit line to the material. If material is not included in the article's Creative Commons licence and your intended use is not permitted by statutory regulation or exceeds the permitted use, you will need to obtain permission directly from the copyright holder. To view a copy of this licence, visit http://creativecommons.org/licenses/by/4.0/ The Creative Commons Public Domain Dedication waiver (http://creativecommons.org/publicdomain/zero/1.0/) applies to the data made available in this article, unless otherwise stated in a credit line to the data. 
(Continued from previous page)

Conclusions: No formal education and not attending four ANC visits were associated with poor knowledge of preeclampsia. While participants who visited health facilities during the first trimester, who gave birth at health facilities, and those who experienced a complication in previous births were more likely to be knowledgeable on preeclampsia. Improving the numbers of ANC visits and encouraging facility delivery are important measures to improve women's knowledge on preeclampsia. Health education regarding preeclampsia risk factors, symptoms, and complications shall be emphasized.

Keywords: Preeclampsia, Knowledge, Attitude, Maternal mortality, Ethiopia

\section{Background}

Preeclampsia has the greatest impact on maternal mortality which complicates nearly a tenth of pregnancies worldwide [1-4]. It is the second leading cause of direct maternal death and directly responsible for 70,000 maternal deaths annually at the global level $[4,5]$ although the exact prevalence of morbidity and mortality related to preeclampsia is not reported in the developing countries. Preeclampsia is one of the top five maternal mortality causes and responsible for $16 \%$ of direct maternal death in Ethiopia [6-8]. The majority of deaths related to preeclampsia could be averted by evidence-based, effective, and timely interventions by increasing women's knowledge and changing attitudes towards preeclampsia $[9,10]$.

Studies indicated that pregnant women have poor knowledge and wrong perception about preeclampsia despite its relevance for early identification and management of the problem [8, 11]. A study conducted in a District Hospital in Tanzania indicated that $60 \%$ of the study participants did not know the consequences of preeclampsia. Lack of knowledge is found to be the predisposing factor to practice risky behaviors for preeclampsia. In the same way, poor understanding of the disease leads to anxiety and becomes a source of stress to the family as well $[12,13]$.

Globally, the maternal mortality ratio declined to 216 per 100, 000 live births from 385 to 100,000 live births in 2015 [14] despite the reduction was not consistent across countries. Countries have to strive hard to accomplish the Sustainable Development Goals (SDGs) which demands more commitment than Millennium Development Goals (MDGs) [15]. Morbidity and mortality related to preeclampsia might be attributed to poor knowledge and negative attitude of pregnant women.

There are several problems related to preeclampsia prevention and diagnosis such as challenges in the prediction, prevention, delay in transport, and management of preeclampsia which are complemented by the shortage of trained health personnel and poor health infrastructures in developing countries [11]. To address the burden of preeclampsia-related consequences, shifting from clinic-based care to community-based case- ascertainment and treatment are key intervention strategies especially in resource-limited areas [5]. Studies conducted in different parts of the world indicated that there is a significant gap among pregnant women related to knowledge, attitude, and perception towards preeclampsia [16-18] which directly or indirectly influence health seeking-behavior leading to increased maternal mortality and morbidity $[12,13]$.

A study in Australia revealed that $77 \%$ of women did not know about preeclampsia before diagnosis. Even among women who were diagnosed with preeclampsia, half of them did not understand the seriousness of preeclampsia [16]. Understanding the level of knowledge and attitude of women about preeclampsia is essential to undertake appropriate measures $[16,19]$. To the best of the authors' knowledge, studies are limited in Ethiopia regarding the knowledgeand attitude of pregnant women towards preeclampsia.

\section{Methods}

\section{Study Design and Period}

A multicenter facility-based cross-sectional study design was implemented in four selected hospitals (Debre Tabor General Hospital, Addis Zemen Primary Hospital, Mekane Eyesus Primary Hospital, and Nefas Mewucha Primary Hospital found in South Gondar Zone of Northwest Ethiopia from January 5 to February 5/2020. The four hospitals were selected for the study purpose out of eight hospitals in the Administrative Zone.

\section{Study Population}

All pregnant women who came to receive antenatal care (ANC) services in the selected Hospitals were the source population. While pregnant women who visit the ANC clinics in the selected Hospitals during the study period were the study population. On the other hand, those who visited the ANC clinics for the diagnosis of pregnancy were excluded.

\section{Sample size determination and Sampling procedures}

A single population proportion formula was used to calculate sample size at $95 \%$ confidence interval, $5 \%$ margin of error, and taking proportion (p) of 0.5 (since 
therewas no similar previous study). Thus, a prevalence of $50 \%$ was taken to obtain the maximum possible sample size. After adding a $10 \%$ non-response rate, the final sample was 423. A multistage random sampling technique was used to select study participants by stratifying hospitals as primary and general hospitals. As of 2020, there are 8 hospitals in South Gondar Zone Administration (1 general and 7 primary hospitals). Debre Tabor General Hospital (DTGH) was taken for the general hospital. While, three primary hospitals; Addis Zemen Primary Hospital (AZPH), Mekane Eyesus Primary Hospital (MEPH), and Nefas Mewucha Primary Hospital $(\mathrm{NMPH})$ were selected by lottery method. Then the calculated sample was proportionally allocated to the selected hospitals based on the ANC case load. The individual study participants were selected by systematic random sampling technique. The six-month caseload was assessed for the selected hospitals to proportionally allocate the sample. By converting the six-month caseload to four weeks (the proposed data collection period), sampling interval was identified. Hence, the four weeks ANC case load in DTGH, AZPH, MEPH, and NMPH were $1200,360,320$, and 340 respectively. Therefore, the allocated samples were 229, 68, 61, and 65 for DTGH, AZPH, MEPH, and NMPH respectively. A sampling interval of 5 was used to select the study participants.

\section{Variables and Measurements Knowledge}

The knowledge of the study participants was assessed using the modified Bloom's cut-off point [20]. The knowledge of the study participants was categorized as good if the participants scored between 80 and $100 \%$ (12-15 points), moderate if scored between 50 and $79 \%$ (7.5-11 points), and poor if they scored less than $50 \%$ ( $<7.5$ points). For the sake of data management, those who had a score of $80-100 \%$ and those with a score of $<80 \%$ were reported as having good knowledge and not having good knowledge (moderate and poor knowledge) respectively.

\section{Attitude}

Attitude was reported as positive, neutral and negative when they scored $80-100 \%, 60-79 \%$, and less than $60 \%$ of the attitude assessment questions respectively using the Bloom's cut-off point [20].

\section{Data Collection Procedures and Quality Assurance}

Data were collected using a structured questionnaire through face to face interview. The questionnaire was adapted from different published literature [19, 21, 22]. A pretest of the questionnaire was conducted on 22 pregnant women outside the study area to undertake necessary amendments. The number of participants included in the pretest was $5 \%$ of the number of pregnant women calculated as the sample size. The data collection tool has four sections. These are sociodemographic parts, obstetric characteristics, knowledge, and attitude measurement questions related to preeclampsia. The questionnaire was prepared in English, translated to Amharic, and then back to English to ensure consistency. To ascertain data quality, data collection and supervision were facilitated by trained health professionals. Training was given for data collectors and supervisors for two days duration to minimize measurement bias. Data collected for pretesting was not included in the final report of the research.

\section{Data Management and Analysis}

Data were entered in a template prepared in EpiData version 3.1 and exported to SPSS version 23 data cleaning, editing, and analysis. Descriptive statistics such as frequency and percentage were used to describe the characteristics of the study participants.

Variables with a P-value of $\leq 0.2$ in bivariable logistic regression were entered in the multivariable model to identify factors associated with the level of knowledge of pregnant women towards preeclampsia. Variance Inflation Factor (VIF) was used to check the possible multicollinearity between independent variables. VIF of $\geq 10$ was used as cutoff point for the presence of multicollinearity between independent variables. The HosmerLemeshow goodness of fit test was used to assess the fitness of the multivariable model. The HosmerLemeshow goodness of fit test indicated that the multivariable model was fit at $\mathrm{X}^{2}=12.95$ with $\mathrm{P}$-value of 0.114. In the multivariable model, a P-value of $\leq 0.05$ was used to decide statistical significance at a $95 \%$ confidence level.

\section{Ethical Consideration}

Ethical clearance was obtained from the research ethics committee of the College of Health Sciences in Debre Tabor University. Written consent was obtained from each study participant after a detailed description of the study aims. The privacy of respondents and confidentiality of information was ensured.

\section{Results \\ Socio-demographic characteristics of the Study participants}

In this study, 410 women who visited the selected hospitals for ANC visits were completed the interview giving a response rate of $96.93 \%$. The mean and the median age of the study participants were found to be 28.42 and 28 years respectively with a range of 17 to 45 years. A high proportion, 334 (81.5\%) of the study participants 
were found in age ranges of 17-34 years while 76 $(18.5 \%)$ were found in age groups of $35-45$ years.

A High proportion of the study participants were Urban residents 277 (67.6\%), in union 391 (95.4\%), and housewives 167 (40.7\%). The median monthly household income of the study participants was 3000 ETB (United States Dollar (USD) 94.37\$) with a minimum and maximum income of 400 ETB (USD 12.58\$) and 20, 000 ETB (USD 629.13\$) respectively (Table 1 ).

\section{Obstetrics and medical condition of the study participants}

With regards to the numbers of births, 88 (21.5\%) and $30(7.3 \%)$ of the study participants were primiparous (para 1) and grand multiparous (para 5 and above) respectively. Among participants who had a history of previous births, 179 (68.06\%) have reported as they gave birth at health facilities while 84 $(31.94 \%)$ reported as they gave birth at home. More than a quarter, $70(26.62 \%)$ of the study participants reported that they have experienced complications in their previous births.
Concerning the family history of a medical condition, $20(4.9 \%)$ and $8(2 \%)$ had a family history of chronic hypertension and diabetes mellitus respectively (Table 2).

\section{The knowledge and attitude of pregnant women towards preeclampsia}

In this study, 92 (22.45\%), 200 (48.8\%), and 118 (28.8\%) of the study participants had poor, moderate, and good knowledge on preeclampsia respectively.

With regards to attitude towards preeclampsia, 26 (6.3\%), 264 (64.4\%), and $120(29.3 \%)$ of the study participants had negative, neutral, and positive attitudes towards the risk factors, the prevention, symptoms, and complications of preeclampsia. Most women agreed that early health-seeking 345 (84.2\%) and having regular ANC follow-up 340 (82.9\%) can reduce the complications related to preeclampsia. On the other hand, significant numbers of women were unsure whether reduced urine output 173 (42.2\%) and convulsion 139 (33.9\%) are related to preeclampsia or not (Table 3$)$.

Table 1 Socio-demographic characteristics of pregnant women in selected Hospitals of South Gondar Zone, Ethiopia, 2020

\begin{tabular}{|c|c|c|c|c|}
\hline Variables & Frequency $(\mathrm{N})$ & Percent (\%) & Chi-square $\left(X^{2}\right)$ & $P$-value \\
\hline \multicolumn{5}{|l|}{ Age in years } \\
\hline $17-34$ & 334 & 81.5 & 0.356 & 0.55 \\
\hline $35-45$ & 76 & 18.5 & & \\
\hline \multicolumn{5}{|l|}{ Residence } \\
\hline Urban & 277 & 67.6 & 6.906 & 0.009 \\
\hline Rural & 133 & 32.4 & & \\
\hline \multicolumn{5}{|l|}{ Marital status } \\
\hline In union & 391 & 95.4 & 1.726 & 0.19 \\
\hline Not in union & 19 & 4.6 & & \\
\hline \multicolumn{5}{|l|}{ Education level } \\
\hline No formal education & 131 & 32.0 & 23.785 & $<0.001$ \\
\hline Primary education & 102 & 24.9 & & \\
\hline Secondary education & 103 & 25.1 & & \\
\hline College and above & 74 & 18.0 & & \\
\hline \multicolumn{5}{|l|}{ Occupation } \\
\hline Housewife & 167 & 40.7 & 19.918 & 0.001 \\
\hline Merchant & 100 & 24.4 & & \\
\hline Daily laborer & 13 & 3.2 & & \\
\hline Farmer & 62 & 15.1 & & \\
\hline Government employee & 68 & 16.6 & & \\
\hline \multicolumn{5}{|c|}{ Monthly household income } \\
\hline$<3000$ ETB $(94.37 \$)$ & 180 & 43.9 & 6.733 & 0.009 \\
\hline$\geq 3000$ ETB (94.37\$) & 230 & 56.1 & & \\
\hline
\end{tabular}

NB Average ETB, USD \$ exchange rate ( 1 \$ $31.79 \mathrm{ETB})$ 
Table 2 Obstetrics and Medical characteristics of pregnant women in selected Hospitals of South Gondar Zone, Ethiopia, 2020

\begin{tabular}{|c|c|c|c|c|}
\hline Variables & Frequency (N) & Percent (\%) & Chi-square $\left(X^{2}\right)$ & P-value \\
\hline \multicolumn{5}{|c|}{ Age at first pregnancy } \\
\hline$<18$ years & 30 & 7.3 & 1.217 & 0.27 \\
\hline$\geq 18$ years & 380 & 92.7 & & \\
\hline \multicolumn{5}{|l|}{ Gravidity } \\
\hline 1 & 147 & 35.9 & 0.831 & 0.660 \\
\hline $2-4$ & 227 & 55.4 & & \\
\hline$\geq 5$ & 36 & 8.8 & & \\
\hline \multicolumn{5}{|l|}{ Parity } \\
\hline 1 & 88 & 21.5 & 1.205 & 0.547 \\
\hline $2-4$ & 145 & 35.4 & & \\
\hline$\geq 5$ & 30 & 7.3 & & \\
\hline \multicolumn{5}{|c|}{ Gestational age at first ANC visit } \\
\hline First trimester & 88 & 21.5 & 5.170 & 0.075 \\
\hline Second trimester & 170 & 41.5 & & \\
\hline Third trimester & 152 & 37.1 & & \\
\hline \multicolumn{5}{|c|}{ Numbers of ANC visits } \\
\hline 1 visit & 150 & 36.6 & 15.453 & $<0.001$ \\
\hline $2-3$ visits & 165 & 40.2 & & \\
\hline$\geq 4$ visits & 95 & 23.2 & & \\
\hline \multicolumn{5}{|l|}{ Last place of birth } \\
\hline Health facility & 179 & 68.06 & 21.841 & $<0.001$ \\
\hline Home & 84 & 31.94 & & \\
\hline \multicolumn{5}{|c|}{ An obstetric complication in the previous births } \\
\hline Yes & 70 & 26.62 & 18.819 & $<0.001$ \\
\hline No & 193 & 73.38 & & \\
\hline \multicolumn{5}{|c|}{ Family history of HTN } \\
\hline Yes & 20 & 4.9 & 4.619 & 0.032 \\
\hline No & 390 & 95.1 & & \\
\hline \multicolumn{5}{|c|}{ Family history of DM } \\
\hline Yes & 8 & 2.0 & 0.057 & 0.811 \\
\hline No & 402 & 98.0 & & \\
\hline
\end{tabular}

Table 3 Attitude towards preeclampsia among pregnant women in selected Hospitals of South Gondar Zone, Ethiopia, 2020

\begin{tabular}{|c|c|c|c|}
\hline Attitude related questions & Agree N(\%) & Unsure $\mathrm{N}(\%)$ & Disagree $\mathrm{N}(\%)$ \\
\hline Avoiding stress reduces the risk of preeclampsia & $261(63.6)$ & $22(5.4)$ & 127(31.0) \\
\hline Having regular ANC is used to prevent preeclampsia & $340(82.9)$ & $47(11.5)$ & $23(5.6)$ \\
\hline Taking fruit and vegetable foods can reduce the risk of preeclampsia & $262(63.9)$ & $56(13.7)$ & $92(22.4)$ \\
\hline Reducing high coffee consumption reduces the risk of preeclampsia & $234(57.1)$ & $90(22.0)$ & $86(21.0)$ \\
\hline Avoiding alcohol consumption reduces the risk of preeclampsia & $214(52.2)$ & $154(37.6)$ & $42(10.2)$ \\
\hline Preeclampsia is serious for the health of the mother & $323(78.80)$ & $72(17.6)$ & $15(3.7)$ \\
\hline Preeclampsia is dangerous for the fetus in the womb & $333(81.2)$ & $63(15.4)$ & $14(3.4)$ \\
\hline Early health-seeking related to preeclampsia reduces complication & $345(84.2)$ & $52(12.7)$ & $13(3.1)$ \\
\hline Convulsion is the consequence of preeclampsia & $252(61.5)$ & $139(33.9)$ & $19(4.6)$ \\
\hline Reduced urine output is related to the consequence of preeclampsia & $107(26.0)$ & $173(42.2)$ & $130(31.7)$ \\
\hline
\end{tabular}




\section{Factors associated with knowledge of preeclampsia} among pregnant women

The education level of the study participants, gestational age at ANC booking, numbers of ANC visits, last place of birth, and experience of complications were found to be significantly associated with knowledge of preeclampsia in this study (Table 4).

The odds of having good knowledge on preeclampsia were found to be low among women who did not attend any formal education compared with those who attended college and above level of education $(\mathrm{AOR}=0.22,95 \%$ CI $(0.06,0.85))$. Women who visited health facilities for ANC booking in the first trimester were more likely to have good knowledge on preeclampsia compared to those who visited health facilities for ANC booking in the third trimester of pregnancy $(\mathrm{AOR}=6.59,95 \% \mathrm{CI}(1.43,30.33))$. Similarly, the number of ANC visits was found to be the predictor of having good knowledge of preeclampsia. Women who had only one ANC visit were less likely to have good knowledge on preeclampsia compared with those who attended four and more ANC visits $(\mathrm{AOR}=0.13,95 \% \mathrm{CI}(0.03,0.59))$.

With regards to the last place of birth, women who gave birth at health facilities in their last birth were 2.61 times more likely to have good knowledge on preeclampsia compared with their counterparts (AOR = 2.61, 955 CI $(1.03,6.61))$. Likewise, participants who experienced obstetric complications in their previous births were 3.67 times more likely to have good knowledge of preeclampsia compared with counterparts $(\mathrm{AOR}=3.67,95 \% \mathrm{CI}(1.78,7.57))$. However, a statistically significant association was not found between the place of residence, occupation of the women, monthly household income, and family history of hypertension in the multivariable model while controlling for confounding factors.

\section{Discussion}

Preeclampsia has a high case fatality rate compared with other pregnancy-induced hypertensive disorders. Hence, aside from diagnosing and treating patients who seek treatment, assessing the level of knowledge and attitude towards preeclampsia is relevant to design appropriate intervention mechanisms for the community $[6,23]$. The purpose of this study was to assess the level of knowledge and attitude of pregnant women towards preeclampsia and its associated factors in the selected Hospitals of South Gondar Zone. The education status of the participants, gestational age at the first ANC booking, numbers of ANC visits, last place of birth, and obstetric complications in previous births were found to be significant predictors of having knowledge of preeclampsia.
Similar to a previous study [24], the level of good knowledge on preeclampsia among women who receive ANC in selected hospitals of South Gondar Zone was $118(28.8 \%)$. The finding of our study is higher than a study conducted in Ghana [25]. But lower than a study conducted at Hospitals of northern Ethiopia which was conducted about pregnancy-induced hypertension [26]. The discrepancy might be related to the variations between the scopes of the study in which the aforementioned study was conducted about pregnancy-induced hypertension in general in contrast to our study which was about preeclampsia. Similarly, the variation in the measurement of the outcome variable might be the reason for the discrepancy. The Bloom's knowledge classification was used in our study in contrast to the study in northern Ethiopia which used the mean knowledge score.

A significant difference in the level of knowledge was observed across different signs and symptoms of preeclampsia which varies from 383 (93.4\%) high blood pressure and $92(22.4 \%)$ genital bleeding as a symptom of preeclampsia. The finding of our study is in congruent with a previous study [8]. With regards to attitude towards preeclampsia, $120(29.3 \%)$ of the study participants had a positive attitude towards the risk factors, the prevention, signs, and symptoms of preeclampsia in this study. A similar finding was reported in a study conducted in Naples, Italy which stated only $21.7 \%$ of the study participants were found to be worried about pregnancy risk factors [12].

The finding of our study indicated that the education level of the study participants was found to be significantly associated with the level of knowledge on preeclampsia. Participants who did not attend any formal education were less likely to be knowledgeable on preeclampsia compared with those who attended college and above level of education (AOR $=0.22,95 \%$ CI $(0.06$, $0.85)$ ). The finding of this study is found to be supported by studies conducted in Ghana [25] and India [23]. The finding of this study publicized that improving female education is an important means of addressing reproductive health problems aside from fulfilling the international commitment of eliminating gender disparities in education at the end of 2030 which is targeted by the SDGs [15].

With regards to the timing of ANC visits, participants who visited health facilities for booking in the first trimester were 6.59 times more likely to have good knowledge on preeclampsia compared with those who visited health facilities for ANC booking in the third trimester (AOR $=6.59,95 \%$ CI $(1.43,30.33)$. Those who visited the health facilities for ANC booking in the first trimester have the opportunity to follow counseling about a healthy lifestyle such as a balanced diet, avoiding stress, 
Table 4 Multivariable analysis of factors associated with knowledge of preeclampsia among pregnant women in selected Hospitals of South Gondar Zone, Ethiopia, 2020

\begin{tabular}{|c|c|c|c|c|}
\hline \multirow[t]{2}{*}{ Variables } & \multicolumn{2}{|c|}{ Have good Knowledge } & \multirow{2}{*}{$\begin{array}{l}\text { COR with } 95 \% \\
\text { Cl }\end{array}$} & \multirow{2}{*}{$\begin{array}{l}\text { AOR with } 95 \% \\
\mathrm{Cl}\end{array}$} \\
\hline & Yes N (\%) & No $N(\%)$ & & \\
\hline \multicolumn{5}{|l|}{ Residence $(N=410)$} \\
\hline Urban & $91(77.1)$ & $186(63.7)$ & $1.92(1.18,3.14)^{\mathrm{a}}$ & $1.21(0.50,2.91)$ \\
\hline Rural & $27(22.9)$ & $106(36.3)$ & 1 & 1 \\
\hline \multicolumn{5}{|l|}{ Marital status $(N=410)$} \\
\hline In union & $110(93.2)$ & $281(96.2)$ & $0.54(0.21,1.37)$ & $0.69(0.17,2.79)$ \\
\hline Not in union & $8(6.8)$ & $11(3.8)$ & 1 & 1 \\
\hline \multicolumn{5}{|c|}{ The education level of the participants $(N=410)$} \\
\hline No formal education & $23(19.5)$ & $108(37.0)$ & $0.21(0.11,0.40)^{\mathrm{a}}$ & $0.22(0.06,0.85)^{b}$ \\
\hline Primary education & $23(19.5)$ & $79(27.1)$ & $0.29(0.15,0.56)^{\mathrm{a}}$ & $0.28(0.07,1.07)$ \\
\hline Secondary education & $35(29.7)$ & $68(23.3)$ & $0.52(0.28,0.95)^{a}$ & $0.79(0.23,2.68)$ \\
\hline College and above & $37(31.4)$ & $37(12.7)$ & 1 & 1 \\
\hline \multicolumn{5}{|c|}{ Occupation of the participants $(N=410)$} \\
\hline Housewife & $46(39.0)$ & $134(45.9)$ & $0.41(0.23,0.73)^{a}$ & $1.76(0.53,5.85)$ \\
\hline Merchant & $33(28.0)$ & $67(22.9)$ & $0.59(0.31,1.11)$ & $2.80(0.77,10.20)$ \\
\hline Farmer & $8(6.8)$ & $54(18.5)$ & $0.18(0.07,0.43)^{\mathrm{a}}$ & $1.16(0.24,5.56)$ \\
\hline Government employee & $31(26.3)$ & $37(12.7)$ & 1 & 1 \\
\hline \multicolumn{5}{|c|}{ Monthly household income $(N=410)$} \\
\hline$<3000$ ETB & $40(33.9)$ & $140(47.9)$ & $0.56(0.36,0.87)^{\mathrm{a}}$ & $1.46(0.64,3.34)$ \\
\hline$\geq 3000$ ETB & $78(66.1)$ & $152(52.1)$ & 1 & 1 \\
\hline \multicolumn{5}{|c|}{ Gestational age at first ANC booking $(N=410)$} \\
\hline First trimester & $27(22.9)$ & $61(20.9)$ & $0.85(0.49,1.50)$ & $6.59(1.43,30.33)^{b}$ \\
\hline Second trimester & $39(33.1)$ & $131(44.9)$ & $0.57(0.35,0.94)^{a}$ & $0.64(0.23,1.73)$ \\
\hline Third trimester & $52(44.1)$ & $100(34.2)$ & 1 & 1 \\
\hline \multicolumn{5}{|c|}{ Numbers of ANC visits $(N=410)$} \\
\hline 1 visit & $32(27.1)$ & $118(40.4)$ & $0.34(0.20,0.60)^{a}$ & $0.13(0.03,0.59)^{b}$ \\
\hline $2-3$ visits & $44(37.3)$ & $121(41.4)$ & $0.46(0.27,0.78)^{a}$ & $0.66(024,1.80)$ \\
\hline$\geq 4$ visits & $42(35.6)$ & $53(18.2)$ & 1 & 1 \\
\hline \multicolumn{5}{|c|}{ Last place of birth $(N=263)$} \\
\hline Health facility & $67(89.3)$ & $112(59.6)$ & $5.68(2.58,12.51)^{a}$ & $2.61(1.03,6.61)^{b}$ \\
\hline Home & $8(10.7)$ & $76(40.4)$ & 1 & 1 \\
\hline \multicolumn{5}{|c|}{ An obstetric complication in the previous births $(N=263)$} \\
\hline Yes & $34(45.3)$ & $36(19.1)$ & $3.50(1.96,6.27)^{\mathrm{a}}$ & $3.67(1.78,7.57)^{\mathrm{b}}$ \\
\hline No & $41(54.7)$ & $152(80.9)$ & 1 & 1 \\
\hline \multicolumn{5}{|c|}{ Family history of HTN $(N=410)$} \\
\hline Yes & $10(8.5)$ & $10(3.4)$ & $2.61(1.06,6.45)^{\mathrm{a}}$ & $2.66(0.71,9.95)$ \\
\hline No & $108(91.5)$ & $282(96.6)$ & 1 & 1 \\
\hline
\end{tabular}

Key: AOR Adjusted Odds Ratio, COR Crude Odds Ratio, ${ }^{a}$ significant in the bivariable model, ${ }^{\mathrm{b}}$ significant in the multivariable model NB: In union refers to being married or living together while not in union refers to single, divorced, or widowed.

and regular checkups in contrast to those who visited health facilities for ANC booking in the third trimester [23]. Moreover, those who visit health facilities for ANC booking in early gestation are likely to be educated so that they might have good knowledge on preeclampsia compared to their counterparts. Hence, encouraging early initiation of ANC visit is crucial to improve women's knowledge on preeclampsia and other 
pregnancy danger signs which also provides the opportunity to implement health promotion interventions in the maternal continuum of care [27].

The number of ANC visits was found to be the predictor of having good knowledge of preeclampsia. Participants who attended only one ANC visit were less likely to have good knowledge on preeclampsia compared with those who attended four and more ANC visits $(\mathrm{AOR}=$ $0.13,95 \%$ CI $(0.03,0.59))$. Those who had four and more ANC visits are likely to be counseled about pregnancy danger signs including preeclampsia causes, risk factors, and prevention mechanisms in every visit. Women who visit ANC clinics at appointment times are likely to be remained about danger signs and healthy diet frequently in contrast to those who had limited ANC visits [26, 28]. The finding of this study suggested that encouraging women to have four and more ANC visits is crucial to increase women's knowledge on preeclampsia aside from enabling them to give birth at health facilities. The finding of our study is supported by a study in India [27].

The place of the last birth was found to be a determinant factor for being knowledgeable on preeclampsia. The odds of having good knowledge on preeclampsia were found to be 2.61 times higher among women who gave birth to their last child at a health institution compared with those who gave birth at home (AOR $=2.61,95 \% \mathrm{CI}$ $(1.03,6.61))$. The finding of this study implied that those who gave birth at health facilities in the previous births are likely to be counseled about preeclampsia including other danger signs in contrast to their counterparts [28].

Similarly, those who had experienced an obstetric complication in their previous births were 3.67 times more likely to have good knowledge on preeclampsia compared with their counterparts (AOR $=3.67,95 \% \mathrm{CI}$ $(1.78,7.57))$. This finding indicated that women who experienced a certain condition are more likely to be aware of the condition compared to counterparts. Women would seek prompt medical care when they are aware of the likely consequences of the symptoms they experience compared to those who did not have [25].

\section{Conclusions}

No formal education and not attending four or more ANC visits were associated with poor knowledge of preeclampsia. While participants who visited health facilities during the first trimester, who gave birth at health facilities, and those who experienced a complication in previous births were more likely to be knowledgeable on preeclampsia. Improving the numbers of ANC visits and encouraging facility delivery are important measures to improve women's knowledge on preeclampsia. Health education regarding preeclampsia risk factors, symptoms, and complications shall be emphasized at times of ANC visits.

\section{Abbreviations}

AZPH: Addis Zemen Primary Hospital; ANC: Antenatal Care; ETB: Ethiopian Birr; DTGH: Debre Tabor General Hospital; MEPH: Mekane Eyesus Primary Hospital; NMPH: Nefas Mewucha Primary Hospital; MDGs: Millennium Development Goals; SDGs: Sustainable Development Goals; USD: United States Dollar; VIF: Variance Inflation Factor

\section{Acknowledgements \\ The authors are indebted to Debre Tabor University College of Health Sciences for approving the ethical review process. The authors are also pleased to thank supervisors, data collectors, and study participants.}

\section{Authors' contributions}

MM contributed to the notion, write up of the proposal, data collection, supervision, data entry, data cleaning, data analysis, and final manuscript write up. Whereas, DA, MB, AM, DG, WAB, and WT involved in the write-up of proposal, supervision of data collection, data analysis, and review of the final manuscript. The final manuscript has been read and approved by all authors.

\section{Funding}

The study was funded by Debre Tabor University. With regards to the fund we do not have a grant number. The funding body had no role in the design, data collection, analysis, interpretation, or write-up apart from supporting the financial expense related to the study.

Availability of data and materials

All relevant data are available in the manuscript and its Supporting Information files without restriction.

\section{Ethics approval and Consent to participate}

The research was approved by the research ethics committee of the College of Health Sciences in Debre Tabor University. Written consent was obtained from each study participant following a detailed description of the study aims. The privacy of respondents and confidentiality of information was ensured.

\section{Consent for publication}

Not applicable.

\section{Competing interest}

We declare no competing interests.

\section{Author details}

${ }^{1}$ Department of Midwifery, College of Health Sciences, Debre Tabor University, Debre Tabor, Ethiopia. ${ }^{2}$ Department of Pediatrics and Child Health Nursing, College of Health Sciences, Debre Tabor University, Debre Tabor, Ethiopia. ${ }^{3}$ Department of Public Health, College of Health Sciences, Debre Tabor University, Debre Tabor, Ethiopia.

Received: 18 December 2020 Accepted: 16 February 2021 Published online: 23 February 2021

\section{References}

1. WHO/RHR. WHo recommendations for Prevention and treatment of preeclampsia and eclampsia Implications and Actions2013.

2. Abalos E, Cuesta C, Grosso A, Chou D, Say L. Global and regional estimates of preeclampsia and eclampsia: a systematic review. ELSEVIER: European Journal of Obstetrics Gynecology Reproductive Biology. 2013;170(1):1-7.

3. Duley L. The Global Impact of Pre-eclampsia and Eclampsia. Elsevier Inc Semin Perinatol. 2009;33:130-7.

4. Townsend R, O'Brien P, Khalil A. Current best practice in the management of hypertensive disorders in pregnancy. Integrated blood pressure control. 2016;9:79-94.

5. Firoz T, Sanghvi H, Merialdi M, von Dadelszen P. Pre-eclampsia in low and middle income countries. Best practice research Clinical obstetrics gynaecology. 2011;25(4):537-48. 
6. Gaym A, Bailey P, Pearson L, Admasu L, Gebrehiwot Y. Ethiopian National EmONC Assessment Team. Disease burden due to pre-eclampsia/eclampsia and the Ethiopian health system's response. International Journal of Gynecology and Obstetrics 2011;115(2011):112-6.

7. Berhan Y, Berhan A. Causes of maternal mortality in Ethiopia: A significant decline in abortion related death, Systematic Review Ethiop J Health Sci. 2014(special issue):15-28.

8. Savage AR, Hoho L. Knowledge of pre-eclampsia in women living in Makole Ward, Dodoma, Tanzania. Afr Health Sci. 2016;16(2):412-9.

9. Sutan R, Hassan H, Shamsuddin K. Health Information Seeking Behaviour among Hypertensive Disorder In Pregnancy (HDP) High Risks Antenatal Mothers. Women's Health Gynecology. 2016;2:(7).

10. Vidler M, Charantimath U, Katageri G, Ramadurg U, Karadiguddi C, Sawchuck D, et al. Community perceptions of pre-eclampsia in rural Karnataka State, India: a qualitative study. Reproductive Health. 2016;13:1

11. Osungbade KO, Ige OK. Public health perspectives of preeclampsia in developing countries: implication for health system strengthening. Journal of pregnancy. 2011;2011:481095.

12. Esposito G, Ambrosio R, Napolitano F, Di Giuseppe G. Women's Knowledge, Attitudes and Behavior about Maternal Risk Factors in Pregnancy. PloS one. 2015;10(12):e0145873.

13. Ejike DE, Ambrose B, Moses DA, Karimah MR, Iliya E, Sheu OS, et al. Determination, knowledge and prevalence of pregnancy-induced hypertension/eclampsia among women of childbearing age at Same District Hospital in Tanzania. International Journal of Medicine Medical Sciences. 2018;10(2):19-26.

14. Alkema L, Chou D, Hogan D, Zhang S, Moller A-B, Gemmill A, et al. Global, regional, and national levels and trends in maternal mortality between 1990 and 2015, with scenario-based projections to 2030: a systematic analysis by the UN Maternal Mortality Estimation Inter-Agency Group. The lancet 2015.

15. United Nations. Transforming our world: The 2030 agenda for sustainable development United Nations 2014

16. East C, Conway K, Pollock W, Frawley N, Brennecke S. Women's experiences of preeclampsia: Australian action on preeclampsia survey of women and their confidants. Journal of pregnancy. 2011;2011:375653.

17. Ouasmani F, Engeltjes B, Haddou Rahou B, Belayachi O, Verhoeven C. Knowledge of hypertensive disorders in pregnancy of Moroccan women in Morocco and in the Netherlands: a qualitative interview study. BMC Pregnancy Childbirth. 2018;18(1):344.

18. Akeju DO, Oladapo OT, Vidler M, Akinmade AA, Sawchuck D, Qureshi R, et al. Determinants of health care seeking behaviour during pregnancy in Ogun State, Nigeria. Reprod Health. 2016;13(Suppl 1):32.

19. Boene H, Vidler M, Sacoor C, Nhama A, Nhacolo A, Bique C, et al. Community perceptions of pre-eclampsia and eclampsia in southern Mozambique. Reprod Health. 2016;13(Suppl 1):33.

20. Bloom BS. Learning for mastery. instruction and curriculum. regional education laboratory for the Carolinas and Virginia. Evaluation comment. 1968; 1(2): 1-12.

21. Fadare R, Akpor O, Oziegbe O. Knowledge and Attitude of Pregnant Women towards Management of Pregnancy-induced Hypertension in Southwest Nigeria. Journal of Advances in Medical Pharmaceutical Sciences. 2016;11(2):1-10.

22. Tunau Ka AAN. The Perception of Patients' Relations on the Cause of Eclampsia. Gynecology \& Obstetrics. 2014;04(02).

23. José N, Raddi S, Kharde S. Assess the Knowledge Regarding Pre-eclampsia and Its Self-care Measures among Antenatal Women Attending Antenatal Outpatient Department of KLES Dr Prabhakar Kore Hospital, Belgaum. South Asian Federation of Obstetrics Gynecology. 2010;2(2):157-62.

24. Jabeen M, Akhter D, Shimul S. U. S. Health Seeking Behavior of Women with Eclampsia Attending at Institute of Child and Mother Health in Dhaka City. Medicine today. 2018:30(02).

25. Fondjo L, Boamah V, Fierti A, Gyesi D, Owiredu E. Knowledge of preeclampsia and its associated factors among pregnant women: a possible link to reduce related adverse outcomes. BMC pregnancy and childbirth. 2019;19(456).

26. Berhe A, llesanmi A, Aimakhu C, Bezabih A. Awareness of pregnancy induced hypertension among pregnant women in Tigray Regional State, Ethiopia Pan African Medical Journal. 2020;35(71).

27. Babbar K, Armo M, Murthy M. Burden of eclampsia: a persisting problem in the developing countries. International Journal of Reproduction Contraception, Obstetrics and Gynecology. 2015:1029-33.
28. Mekie M, Mekonnen W, Assegid M. Cohabitation duration, obstetric behavioral and nutritional factors predict preeclampsia among nulliparous women in West Amhara Zones of Ethiopia: Age matched case control study. PloS one. 2020;15(1):e0228127.

\section{Publisher's Note}

Springer Nature remains neutral with regard to jurisdictional claims in published maps and institutional affiliations.

\section{Ready to submit your research? Choose BMC and benefit from:}

- fast, convenient online submission

- thorough peer review by experienced researchers in your field

- rapid publication on acceptance

- support for research data, including large and complex data types

- gold Open Access which fosters wider collaboration and increased citations

- maximum visibility for your research: over $100 \mathrm{M}$ website views per year

At $\mathrm{BMC}$, research is always in progress.

Learn more biomedcentral.com/submissions 